\title{
Open reduction and internal fixation of acetabular fractures in patients of old age
}

\author{
Pol Maria Rommens ${ }^{1}$ (D) . Roland Schwab ${ }^{1} \cdot$ Kristin Handrich $^{1} \cdot$ Charlotte Arand $^{1} \cdot$ Daniel Wagner $^{1}$. \\ Alexander Hofmann ${ }^{2}$
}

Received: 31 December 2019 / Accepted: 17 June 2020 / Published online: 30 July 2020

(C) The Author(s) 2020

\begin{abstract}
There is an ongoing debate on which treatment for acetabular fractures in elderly patients is the most appropriate. This study was set up to identify the role of open reduction and internal fixation of acetabular fractures in persons of old age.

Material and methods We retrospectively reviewed the medical charts and radiological data of all patients older than 65 years, who suffered an isolated acetabular fracture and were admitted in our Department between 2010 and 2014 (5-year period). Complications, outcome and mortality were recorded. Of all surviving patients, quality of life (QoL), mobility and independence were graded with European Quality of Life 5 Dimensions 3 Level (EQ-5D-3L), European Quality of Life 5 Dimensions Visual Analogue Scale (EQ-5D-VAS), Numeric Rating Scale (NRS), Elderly Mobility Scale (EMS) and Tinetti Mobility Test (TMT). Results Seventy patients could be identified. There were 52 men (74\%) and 18 women (26\%) with a median age of 79.0 years (range: 65-104 years). Forty-six patients (66\%) had been treated with open reduction and internal fixation (ORIF), 24 (34\%) conservatively. There were negative predictive factors - subchondral impaction, damage to the femoral head and multiple fragments - in 54\% of the operative group. With ORIF, an anatomical reduction could be achieved in 27 patients (59\%), an acceptable in $18(39 \%)$ and a poor in one (2\%). At follow-up, 18 patients $(26 \%)$ had died and $23(33 \%)$ were not able to participate. The follow-up rate of the surviving operatively treated patients was $77 \%$. Eleven of 46 operated patients (24\%) needed a conversion to a total hip arthroplasty (THA). All patients undergoing conversion had imperfect reduction after surgery. No patient in the non-operative group underwent conversion to THA during follow-up. The median follow-up time of operatively treated patients without conversion ( $n=17)$ was 30 months (range, 16-73 months), of patients with THA $(n=9) 30$ months after conversion (range, 17-55 months). Quality of reduction correlated to QoL, mobility and independence in all recorded parameters. Patients with secondary THA had similar good outcomes as patients after ORIF without later conversion. Men had better outcome than women.

Conclusion ORIF of acetabular fractures in patients of old age results in excellent outcomes at short-term follow-up when anatomical reduction can be achieved. In case of negative predictive factors, ORIF cannot be regarded as a definitive solution, rather as the construction of a stable socket for secondary THA. The decision of therapy should be made dependent on preoperative radiographic parameters.
\end{abstract}

Keywords Acetabulum $\cdot$ Fracture $\cdot$ Open reduction internal fixation $\cdot$ Complications $\cdot$ Outcome $\cdot$ Radiologic parameters

Level of evidence: III, retrospective cohort study

Pol Maria Rommens

pol.rommens@unimedizin-mainz.de

Roland Schwab

Schwab.Roland@outlook.de

Kristin Handrich

Kristin.Handrich@unimedizin-mainz.de

Charlotte Arand

Charlotte.arand@unimedizin-mainz.de
Daniel Wagner

Wagner.daniel@gmx.ch

Alexander Hofmann

Hofmann.trauma-surgery@gmx.net

1 Department of Orthopaedics and Traumatology, University Medical Center, Langenbeckstrasse 1, 55131 Mainz, Germany

2 Department of Orthopaedics and Traumatology, Westpfalz Klinikum Kaiserslautern, Hellmut-Hartert Straße 1, 67655 Kaiserslautern, Germany 


\section{Introduction}

Acetabular fractures are often the result of a high-energy trauma such as a traffic accident or a fall from a great height [1-4]. Yet, we are increasingly confronted with fractures due to lowenergy trauma. The percentage of persons older than 65 years has grown from 16 to $21 \%$ between 1994 and 2019 (25-year period) in the German population (https://de.statista.com/ themen/172/senioren/). Consequently, the incidence of acetabular fractures in patients above 65 years has grown as well [5-8]. Today, the majority of the acetabular fracture patient population is constituted by patients of old age [9]. This raises the question of the role of open reduction and internal fixation (ORIF) of acetabular fractures in this patient population. In the study of Tannast et al., age of more than 40 years was an independent predictive factor for conversion to total hip arthroplasty (THA) after ORIF [10]. In older patients, treatment alternatives are not clearly supported by evidence. Long-term outcome studies are rare [11, 12]. Old patients have different characteristics: most have comorbidities with increased operative risk. Functional demands are lower. Bone quality is diminished, which bears the risk of implant loosening. On the other hand, elderly patients should be mobilised timely after trauma. Restricted weight bearing may not be possible. Non-operative treatment has the disadvantage of delayed and painful mobilisation. Joint congruence is not obtainable unless the fracture is not displaced or shows secondary congruence. Some authors prefer non-operative management in specific conditions [13, 14]. Stable cup fixation in primary THA may be challenging in displaced fractures [15]. Due to low bone quality and subchondral impaction, anatomical reduction may not be possible in ORIF [16]. Other solutions as ORIF followed by THA in one or consecutive operation phases are presented, but not supported by large series [17-19]. This study aims at describing the shortterm outcomes of ORIF of acetabular fractures in a cohort of patients of old age. Outcomes are evaluated with regard to morphologic criteria in conventional X-rays and CT data of the fracture and with validated questionnaires.

\section{Patients and methods}

We retrospectively reviewed the medical charts of all patients aged 65 years or older with an isolated acetabular fracture, admitted to our level I trauma centre between 2010 and 2014 (5year period). Approval of this retrospective study has been granted by the local ethics committee (Ethics Commission of the State Chamber of Medicine of Rhineland-Palatinate) (Ref. 837.140.17 (10974)). Polytraumatized patients, acetabular fractures due to malignancies, periprosthetic acetabular fractures and patients with follow-up to less than one year were not included. Demographic data, type of fracture (by the Letournel- classification [20]), type of treatment (operative or non-operative), radiographic result (by the Matta criteria [21]) and perioperative complications were recorded. The following negative outcome predictors were identified on pre-operative radiographs and CT: subchondral impaction, damage to the femoral head and fracture comminution [22]. Date of death was registered for patients who died. All surviving patients were asked to fill in the European Quality of Life 5 Dimensions 3 Level (EQ-5D-3L) questionnaire [23, 24] and the numeric rating scale (NRS) [25]. The timed up-and-go test (TUG) [26], the elderly mobility scale (EMS) [27] and the mobility test of Tinetti (TMT) [28] were performed in all patients with follow-up by one of the coauthors (SR).

Statistical analysis was performed using the SPSS software (IBM SPSS Statistics for Windows, Version 25; IBM Corp, Armonk, NY, USA). A descriptive analysis of demographics, fracture type, therapy inclusive surgical approaches, length of hospital stay, complications, mortality, functional outcome and degree of independence was performed. We further performed a comparison of the treatment results depending on the gender and type of treatment. To ascertain normal distribution, we utilised the Shapiro-Wilk Test. The PRO EQ-5D VAS was normally distributed $(p=0.076)$; the remaining PRO EQ-5D Index Value was not $(p=0.00026)$. $T$ test was used in case of normal distribution and variance homogeneity. In case of variance homogeneity without normal distribution, the MannWhitney $U$ test was used (e.g. to calculate the significance between the EQ-5D Index Value and the gender). When more than two groups were compared, unifactorial ANOVA test was used in case of normal distribution and variance homogeneity. If there was normal distribution without variance homogeneity, we performed the Welch-test. The Kruskal-Wallis test was used in case of variance homogeneity without normal distribution (e.g. the EQ-5D Index Value depending on the quality of reduction). All multivariate tests included a post hoc analysis. A statistically significant difference was present when $p<0.05$. The Kaplan-Meier estimate was used for the presentation of the patient survival rate and for the survival rate of hip joints with or without anatomical reduction.

\section{Results}

Seventy patients were identified. There were 52 men (74\%) and 18 women (26\%). Their median age was 79 years (range, 65-104 years), 8 patients being more than 90 years old. A total of 46 patients $(66 \%)$ had been treated with ORIF, 24 (34\%) had been treated non-operatively. The median age of operatively treated patients was 77 years (range, 65-92 years), of conservatively treated patients 81 years (range, 73-104 years). Seven of eight patients above the age of 90 had been treated conservatively. During the follow-up period, 18 patients (26\%) had died, 12 (26\%) from the operatively treated group 
Table 1 Demographic data

\begin{tabular}{llll}
\hline & Total & Operative & Conservative \\
Number of patients (\%) & $70(100)$ & $46(100)$ & $24(100)$ \\
Age in years: median (range) & $79(65-104)$ & $77(65-92)$ & $81(73-104)$ \\
Mortality: no (\%) & $18(26)$ & $12(26)$ & $6(25)$ \\
& No (\%) & No (\%) & No (\%) \\
Surviving patients & $52(100)$ & $34(100)$ & $18(100)$ \\
Drop-out of surviving & $23(44)$ & $8(23)$ & $15(83)$ \\
Remaining for evaluation & $29(56)$ & $26(77)$ & $3(17)$ \\
\hline
\end{tabular}

and $6(25 \%)$ from the conservatively treated group. A total of 23 patients (33\% of the whole group or $44 \%$ of the survivors) refused participation in the study or were not able to participate (mental illness, loss of mobility): 8 of the operatively treated group $(8 / 34=23 \%)$ and 15 of the conservatively treated group $(15 / 18=83 \%)$. There were 29 patients available for the follow-up examinations, 26 from the operative and 3 from the conservative group. The follow-up rate of the surviving operatively treated patients was $77 \%$. Median time to followup was 36 months (range, 16-73 months). Demographics are depicted in Table 1.

Fractures involving the anterior column and anterior wall represented $90 \%$ of the whole group and $89 \%$ of the operatively treated group with complete follow-up (Table 2).

More than $90 \%$ of operatively treated patients and more than $95 \%$ of the operated patients with complete follow-up were operated through one of the anterior approaches (Table 3).

The median length of hospital stay of all patients was 14 days, in the operatively treated group 16 days and in the conservatively treated group 8 days. Complications occurred in $26 \%$ of patients in the operative and $38 \%$ in the conservative group ( $p=0.32$ ) (Table 4$)$.

Mortality during 5-year follow-up was documented for the entire cohort. There was a 30-day mortality of $9 \%, 7 \%$ in the operative group and $13 \%$ in the conservative group. The one- year mortality was $14 \%: 11 \%$ in the operative group and $21 \%$ in the conservative group. The five-year mortality was $26 \%$, $26 \%$ in the operative and $25 \%$ in the conservative group. The Kaplan-Meier curves for cumulative patient survival of the operative and conservative groups are depicted in Fig. 1.

Negative predictive factors were present in 21 patients (46\%) of the whole operative group. An anatomical reduction could be achieved in 27 patients (59\%). Further details on type and number of negative predictive factors and on the quality of reduction can be seen in Table 5. During follow-up, 11 patients $(16 \%)$ received a THA. No patient with conservative therapy received THA. The ratio of conversion to THA in the operated group was $24 \%$ ( $n=11 / 46)$. All patients, who needed conversion, had an imperfect reduction. There was no conversion in patients with anatomical reduction. There were 3 reasons for conversion to secondary THA. Four patients had implant loosening with secondary fracture displacement. Their conversion took place after one, two, two and four months respectively. One patient had an intra-articular screw with consecutive destruction of the femoral head. THA was performed after five months. Six patients developed a post-traumatic hip osteoarthritis. THA was carried out after four, four, five, 11, 16 and 36 months respectively. The Kaplan-Meier curve of cumulative hip joint survival in patients, who had imperfect reduction after ORIF, is depicted in Fig. 2.

The mean EQ-5D Index Value was 0.82 (SD 0.22) for the group with complete follow-up. The EQ-5D Index Value was 0.80 (SD 0.20) for the age group between 65 and 74, and 0.84 (SD 0.24) for the age group of 75 and above. The median EQ5D Index Value was 0.95 (range 0.31-1.0, IQR 0.89-1.0) for the patient group with anatomical reduction, 0.79 (range 0.40 1.0, IQR 0.72-0.89) for the group with imperfect reduction and 0.11 for the patient with poor reduction $(p=0.029)$. Men had a higher median EQ-5D Index Value of 0.89 (range $0.31-$ 1.0, IQR $0.79-1.0$ ) than women with a value of 0.70 (range 0.11-0.90; IQR 0.48-0.79) $(p=0.016)$.
Table 2 Classification of fractures

\begin{tabular}{lll}
\hline & $\begin{array}{l}\text { All study patients } \\
\text { No }(\%)\end{array}$ & $\begin{array}{l}\text { Follow-up patients with operative treatment } \\
\text { No }(\%)\end{array}$ \\
\hline All patients & $70(100)$ & $26(100)$ \\
Anterior column, posterior hemitransverse & $26(37)$ & $12(46)$ \\
Both column & $25(36)$ & $7(27)$ \\
Anterior column & $10(14)$ & $4(15)$ \\
Anterior wall & $2(2.9)$ & - \\
Posterior wall & $2(2.9)^{`}$ & $1(3.8)$ \\
Posterior column & $2(2.9)$ & - \\
T-type & $2(2.9)$ & $2(7.7)$ \\
Posterior column, posterior wall & $1(1.4)$ & - \\
\hline
\end{tabular}


Table 3 Choice of approaches

\begin{tabular}{lcl}
\hline & $\begin{array}{l}\text { Operatively treated patients } \\
\text { No }(\%)\end{array}$ & $\begin{array}{l}\text { Follow-up patients with operative treatment } \\
\text { No }(\%)\end{array}$ \\
\hline All patients & $46(100)$ & $26(100)$ \\
Ilioinguinal & $36(78)$ & $22(85)$ \\
Kocher-Langenbeck & $4(8.7)$ & $1(3.8)$ \\
Intra pelvic and lateral window & $3(6.5)$ & $2(7.7)$ \\
Intra pelvic & $2(4.3)$ & $1(3.8)$ \\
Iliofemoral & $1(2.2)$ & - \\
\hline
\end{tabular}

The mean EQ-5D VAS was 66 (SD 14) for the whole group with complete follow-up. It was higher in patients with anatomical reduction $(71.1$; SD 9.2) than in patients with imperfect and poor reduction (61.5; SD 16.3). Men had a higher EQ-5D VAS (69.9; SD 11.6) than women (51.5; SD 13.7) $(p=0.002)$.

Median intensity of pain in the NRS of the whole group with complete follow-up was 2. Patients with anatomical reduction reported a median pain intensity of 2; patients with an imperfect reduction reported a median pain intensity of 3 ( $p=$ $0.018)$. Women reported a median pain intensity of 4 compared with men with a median of $2(p=0.004)$.

For the TUG, patients with anatomical reduction needed $17 \mathrm{~s}$ (SD $7 \mathrm{~s}$ ), whereas patients with imperfect reduction needed $24 \mathrm{~s}$ (SD $11 \mathrm{~s})(p=0.057)$. Men needed $17 \mathrm{~s}$, which was significantly less than women with $34 \mathrm{~s}(p<0.001)$. The median EMS of patients with complete follow-up was 17 points. Patients with anatomical reduction reached a mean EMS value of 17 (SD 2.5), whereas patients with imperfect reduction a value of 15 (SD 3.9) $(p=0.223)$. Men had 18 points, which was significantly better than women, who had 12 points $(p=$ 0.04). The median TMT was 23.3 points, which corresponds with a moderate risk of falling. Patients with an anatomical reduction had a mean TMT value of 27 , patients with an imperfect reduction a value of $25(p=0.27)$. Higher values were recorded for men with 27 points than women with 15 points, which means that women had a higher risk of falling than men $(p=0.011)$.

Table 4 In-hospital complications

\begin{tabular}{lll}
\hline Total & $\begin{array}{l}\text { Operative } \\
\text { No }(\%)\end{array}$ & $\begin{array}{l}\text { Conservative } \\
\text { No }(\%)\end{array}$ \\
\hline Number of patients & $46(100)$ & $24(100)$ \\
Pneumonia & $7(15)$ & $6(25)$ \\
Urinary tract infection & $4(8.7)$ & $5(21)$ \\
Decubitus & $3(6.5)$ & $1(4.2)$ \\
Deep wound infection & $1(2.2)$ & - \\
Pulmonary embolism & $1(2.2)$ & - \\
\hline
\end{tabular}

When comparing patients with osteosynthesis as only treatment $(n=17)$ with patients, who received a conversion to THA $(n=9)$, all parameters were slightly better for patients without conversion, but the differences were not statistically significant. The mean EQ-5D Index Value for the patients without conversion was 0.82 (SD 0.25), for the patients with conversion 0.75 (SD 0.15). The median EQ-5D VAS for the patients without conversion was 70 (35-85, IQR 65-76), for the patients with conversion 62 (35-87, IQR 50-64). Further comparative data can be seen in Table 6 .

\section{Discussion}

We retrospectively reviewed 70 patients of old age with acetabular fractures. Nearly three quarters of patients were men. In a study on fragility fractures of the pelvis performed in the same level I trauma centre, more than $80 \%$ were women [29]. The loss of bone strength in the pelvic ring while ageing may be different in women and men [30,31]. Patients, who were treated conservatively (median age, 81 years), were significantly older than patients treated operatively (median age, 77 years). Operative risk, functional demands and life expectancy played an important role in decision-making.

Mortality and drop-out ratios in our patient cohort during follow-up time reflect data of other studies with patients of similar age such as hip fracture patients [32]. Only three nonoperatively treated patients completed follow-up, meaning that no conclusions can be drawn about outcomes in the non-operative group. The $77 \%$ follow-up rate of operatively treated patients is fair. The median follow-up time of the operated group was 36 months (range, 16-73 months). A total of 23 of the 26 operated patients with follow-up had a follow-up time of 24 months or more, which is considered enough to detect most cases of osteoarthritis after acetabular fractures [33].

While analysing the pre-operative conventional radiographs and CT data, we found negative predictive factors in $45 \%$ of the operated fractures. These factors had a major influence on the accuracy of reduction. An anatomical reduction could only be obtained in 59\%. The quality of reduction 
Fig. 1 Kaplan-Meier curves of cumulative patient survival during 5-year follow-up depending on type of treatment

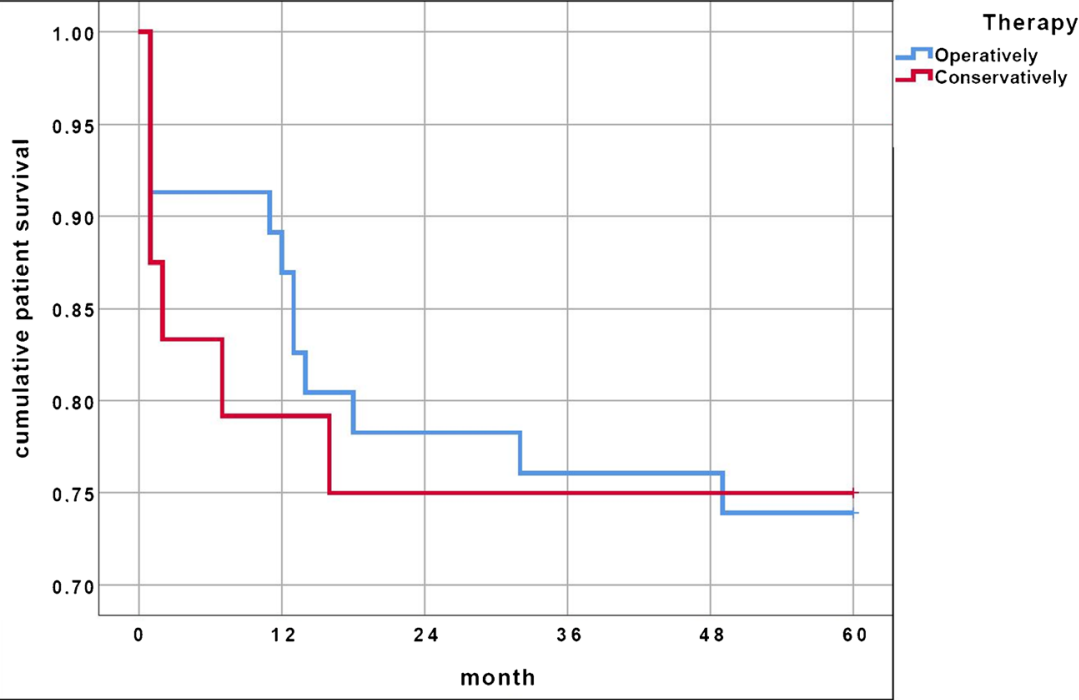

played a decisive role for QoL, functional outcome and necessity of conversion to THA. The EQ-5D Index Value and the EQ-5D VAS were significantly higher in the patients with anatomical reduction than in patients with imperfect reduction. The mean EQ-5D Index Value was 0.95 for the patient group with anatomical reduction and 0.79 for the group with imperfect reduction. For comparison, these values are 0.89 for a previously described German reference population between 65 and 74 years of age and 0.84 for a population older than 75 years [34]. The mean EQ-5D VAS of patients with anatomical reduction was 71.1 and of the patients with imperfect reduction 61.5. Reference values rank between 60 (women above 75 years of age) and 72 (men between 65 and 74 years of age) in a previously described German reference population [35]. Pain intensity (NRS) was graded significantly higher in patients with imperfect reduction. Patients with an anatomical reduction needed $17 \mathrm{~s}$ for the TUG test, whereas patients with an imperfect reduction needed $24 \mathrm{~s}$. The only available reference value for the TUG test gives a much shorter time of $9.2 \mathrm{~s}$ for the age group between 70 and 79 years [35]. The median EMS of patients with complete follow-up was 17 within a maximum of 20 points. As values above 14 stand for independent mobilisation, we can conclude that the majority of patients were independent. Nevertheless, women with a mean value of 12 points scored significantly lower than men. During follow-up, $24 \%$ of the operated patients needed a conversion to THA. All of them had negative predictive factors, imperfect reduction or complications of surgery. There was no conversion in patients with anatomical reduction, which also has been described in previous studies [10, 21, 36].

There were more in-hospital complications in the conservative group than in the operated group (38\% versus $26 \%$ ) although the hospital stay of the conservative group was shorter ( 8 days versus 16 days). Mortality within the first 30 days after trauma was nearly double in the conservative group, but the study did not have statistical power to analyse mortality. Mortality within the first year was still higher in the conservative group but became similar after five years for both groups. The early period after trauma seems to be more critical for the conservative group for what concerns complications and mortality. The higher age of conservatively treated patients may play a decisive role here.
Table 5 Negative predictive factors and quality of reduction

\begin{tabular}{lll}
\hline & $\begin{array}{l}\text { Operated patients } \\
\text { No }(\%)\end{array}$ & $\begin{array}{l}\text { Follow-up patients with operative treatment } \\
\text { No }(\%)\end{array}$ \\
\hline All patients & $46(100)$ & $26(100)$ \\
Gull sign & $7(15)$ & $5(19)$ \\
Additional subchondral impaction & $6(13)$ & $5(19)$ \\
Indentation of femoral head & $6(13)$ & $3(12)$ \\
Fragment comminution & $2(4.3)$ & $1(3.8)$ \\
Anatomical reduction & $27(59)$ & $11(42)$ \\
Not anatomical, acceptable & $18(39)$ & $14(54)$ \\
Poor reduction & $1(2.2)$ & $1(3.8)$ \\
\hline
\end{tabular}


Fig. 2 Kaplan-Meier curve of cumulative hip joint survival during 5-year follow-up of the patients with imperfect and poor reduction. In 27 patients with anatomical reduction, no secondary THA was performed

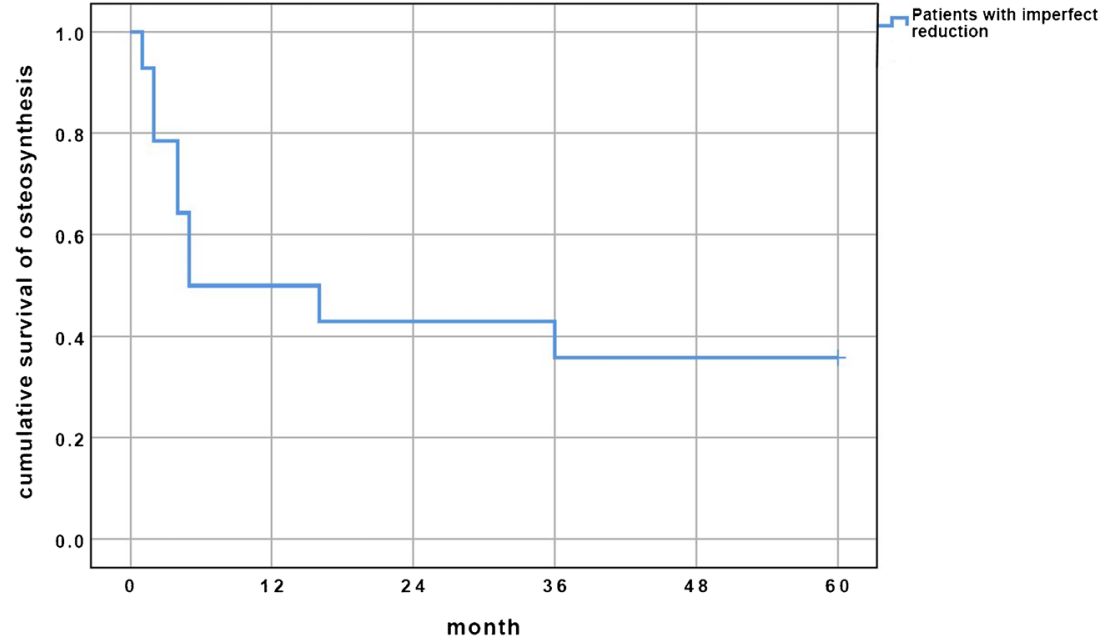

Previous studies on the treatment of acetabular fractures in patients with old age have been published. Helfet et al. presented a series of 18 patients with an average age of 67 years, who had been treated with ORIF. Patients reached an average Harris Hip Score (HHS) of 90 points after two years. The authors concluded that ORIF can obtain good results and avoid the need for a difficult THA in selected patients [36]. Carroll et al. reviewed 93 patients with a mean age of 67 years and a follow-up of five years. The rate of secondary THA was $31 \%$. Poor fracture reduction, development of avascular necrosis and previous contralateral THA were associated with secondary surgery. Functional outcomes were similar to those of younger patients with acetabular fractures and with the noninjured norms [12]. Jeffcoat et al. presented 41 patients with a minimum of two years follow-up. Conversion to THA was needed in 27\% [37]. Rickman et al. presented 12 patients, in which a combination of ORIF and THA were performed in the same operation. Patients were allowed full weight bearing immediately. Outcomes were favourable and complications few. No cup migration was seen after a mean time of 18 months [38]. Mouhsine et al. presented cable fixation in combination with THA. Eleven of 12 patients could be followed up for two years. They had complete fracture healing and good functional outcomes without cup loosening [39]. Salama et al. presented a series of 18 patients with ORIF and THA in one operative procedure. They had an average age of 60 years and a mean follow-up of 22 months (range, 12-36 months). All fractures healed and there was cup loosening in only 1 patient [40]. Borajah et al. reviewed 18 patients with a mean age of 71 years and at least one year followup. They all received ORIF and THA in one operative session. There was one failure of the acetabular component. Mean HHS was 88 [41]. Borg et al. also suggest performing open reduction and internal fixation together with THA in one operative session. No patient of their cohort of 13 patients, who underwent this combined procedure, needed secondary surgery within three years of follow-up [19]. The strategy of combining ORIF with THA may decrease the need for secondary surgery, but may also add to surgical time at the initial operation. Sermon et al. reviewed 121 patients, who received THA after an acetabular fracture. They differentiated between patients who received immediate THA (early THA group) and those who received THA after previous ORIF (late THA group). The revision rate after THA was $22 \%$ in the late
Table 6 Comparison between patients without and with conversion to total hip arthroplasty

\begin{tabular}{lll}
\hline & $\begin{array}{l}\text { Patients without conversion } \\
(n=17)\end{array}$ & $\begin{array}{l}\text { Patients with conversion } \\
(n=9)\end{array}$ \\
\hline $\begin{array}{l}\text { Median follow-up time in months (range) } \\
\begin{array}{l}\text { Median follow-up time after conversion in } \\
\text { months (range) }\end{array}\end{array}$ & $30(16-73)$ & $39(30-60)$ \\
EQ-5D Index Value, mean (SD) & $0.82(0.25)$ & $30(17-55)$ \\
EQ-5D VAS, median (range, IQR) & $70(35-85,65-76)$ & $0.75(0.15)$ \\
NRS, mean (SD) & $2.3(1.5)$ & $62(35-87,50-64)$ \\
TUG, mean (SD) & $18.7(7.4)$ & $3.4(19)$ \\
EMS, mean (SD) & $17(2.5)$ & $24.9(12.6)$ \\
TMT, mean (SD) & $24.7(3.7)$ & $14.8(4.6)$ \\
\hline
\end{tabular}


THA group. This rate was significantly higher than the revision rate of $8 \%$ in the early THA group. Patients with primary THA were significantly older than patients with secondary THA [42]. De Bellis et al. performed a systematic review of 6 studies concerning THA after acetabular fracture. Similar satisfying clinical outcomes were seen after acute or delayed THA [43]. Our results also show similar functional outcomes in patients after ORIF and later conversion to THA, when compared with patients after ORIF only. In our concept, delayed THA aims at safe placement of the cup in a stable and healed acetabular socket.

All abovementioned publications report on small cohorts, with retrospective analysis, and short follow-up times. Our study also has all these limitations. Moreover, the follow-up time of 36 months of our operated group was short. With longer followup time, the rate of conversion to THA may have increased. Although, with a median age of 77 years in the operated group, our study reports on a patient population of old age.

\section{Conclusion}

In the absence of negative prognostic radiographic signs, ORIF of acetabular fractures in patients of old age is feasible and yields very good functional outcomes at short-term follow-up. Besides age and health status, decision-making should be based on the radiological characteristics of the fracture. In case of negative predictive factors, ORIF can be regarded as a way of reconstructing a stable socket for later safe cup implantation.

Funding Information Open Access funding provided by Projekt DEAL.

\section{Compliance with ethical standards}

Conflict of interest The authors declare that they have no conflict of interest.

Open Access This article is licensed under a Creative Commons Attribution 4.0 International License, which permits use, sharing, adaptation, distribution and reproduction in any medium or format, as long as you give appropriate credit to the original author(s) and the source, provide a link to the Creative Commons licence, and indicate if changes were made. The images or other third party material in this article are included in the article's Creative Commons licence, unless indicated otherwise in a credit line to the material. If material is not included in the article's Creative Commons licence and your intended use is not permitted by statutory regulation or exceeds the permitted use, you will need to obtain permission directly from the copyright holder. To view a copy of this licence, visit http://creativecommons.org/licenses/by/4.0/.

\section{References}

1. Letournel E (1993) The treatment of acetabular fractures through the ilioinguinal approach. Clin Orthop Relat Res 292:62-76
2. Rommens PM, Broos PL, Vanderschot P (1997) Preparation and technique for surgical treatment of 225 acetabulum fractures. Two year result of 175 cases. Unfallchírurg 100:338-348

3. Mayo KA (1994) Open reduction and internal fixation of fractures of the acetabulum. Results in 163 fractures. Clin Orthop Relat Res 305:31-37

4. Templeman DC, Olson S, Moed BR, Duwelius P, Matta JM (1999) Surgical treatment of acetabular fractures. Instr Course Lect 48: 481-496 Review

5. Sullivan MP, Baldwin KD, Donegan DJ, Mehta S, Ahn J (2014) Geriatric fractures about the hip: divergent patterns in the proximal femur, acetabulum, and pelvis. Orthopedics. 37(3):151-157

6. Rinne PP, Laitinen MK, Huttunen T, Kannus P, Mattila VM (2017) The incidence and trauma mechanisms of acetabular fractures: a nationwide study in Finland between 1997 and 2014. Injury. 48(10):2157-2161

7. Ochs BG, Marintschev I, Hoyer H, Rolauffs B, Culemann U, Pohlemann T, Stuby FM (2010) Changes in the treatment of acetabular fractures over 15 years: analysis of 1266 cases treated by the German Pelvic Multicentre Study Group (DAO/DGU). Injury. 41(8):839-851

8. Ferguson TA, Patel R, Bhandari M, Matta JM (2010) Fractures of the acetabulum in patients aged 60 years and older: an epidemiological and radiological study. J Bone Joint Surg Br. 92(2):250-257

9. Herath SC, Pott H, Rollmann MFR, Braun BJ, Holstein JH, Höch A, Stuby FM, Pohlemann T (2019) Geriatric acetabular surgery: Letournel's contraindications then and now - data from the German pelvic registry. J Orthop Trauma 33(Supp1 2):S8-S13

10. Tannast M, Najibi S, Matta JM (2012) Two to twenty-year survivorship of the hip in 810 patients with operatively treated acetabular fractures. J Bone Joint Surg Am 94(17):1559-1567

11. Hessmann MH, Nijs S, Rommens PM (2002) Acetabular fractures in the elderly. Results of a sophisticated treatment concept. Unfallchirurg 105(10):893-900 German

12. Carroll EA, Huber FG, Goldman AT, Virkus WW, Pagenkopf E, Lorich DG, Helfet DL (2010) Treatment of acetabular fractures in an older population. J Orthop Trauma 24(10):637-644

13. Walley KC, Appleton PT, Rodriguez EK (2017) Comparison of outcomes of operative versus non-operative treatment of acetabular fractures in the elderly and severely comorbid patient. Eur J Orthop Surg Traumatol 27(5):689-694

14. Ryan SP, Manson TT, Sciadini MF, Nascone JW, LeBrun CT, Castillo RC, Muppavarapu R, Schurko B, O Toole RV. (2017) Functional outcomes of elderly patients with nonoperatively treated acetabular fractures that meet operative criteria. J Orthop Trauma 31(12):644-649

15. Romness DW, Lewallen DG (1990) Total hip arthroplasty after fracture of the acetabulum. Long-term results. J Bone Joint Surg Br 72(5):761-764

16. Anglen JO, Burd TA, Hendricks KJ, Harrison P (2003) The "Gull sign": a harbinger of failure for internal fixation of geriatric acetabular fractures. J Orthop Trauma 17(9):625-634

17. Marchesi DG, Ganz R (1989) Total prosthesis implantation with added pelvic osteosynthesis. Orthopade 18(6):483-488 German

18. Saxer F, Studer P, Jakob M (2011) Open stabilization and primary hip arthroplasty in geriatric patients with acetabular fractures: combination of minimally invasive techniques. Unfallchirurg 114(12): 1122-1127 German

19. Borg T, Hernefalk B, Hailer NP (2019) Acute total hip arthroplasty combined with internal fixation for displaced acetabular fractures in the elderly: a short-term comparison with internal fixation alone after a minimum of two years. Bone Joint J 101-B(4):478-483

20. Judet R, Judet J, Letournel E (1964) Fractures of the acetabulum; classification and surgical approaches for open reduction. Preliminary report. J Bone Joint Surg Am 46:1615-1646 
21. Matta JM (1996) Fractures of the acetabulum. Accuracy of reduction and clinical results in patients managed operatively within three weeks after the injury. J Bone Joint Surg Am 78(11):1632-1645

22. Rommens PM, Ingelfinger $P$, Nowak TE, Kuhn S, Hessmann MH (2011) Traumatic damage to the cartilage influences outcome of anatomically reduced acetabular fractures: a medium-term retrospective analysis. Injury 2 42(10):1043-1048

23. Group TE (1990) EuroQoL - a new facility for the measurement of health-related quality of life. Health Policy (Amsterdam, Netherlands) 3(16):199-208

24. Brooks L (1996) EuroQoL: the current state of the play. Health Policy (Amsterdam, Netherlands) 1(37):53-72

25. Rodriguez CS (2001) Pain measurement in the elderly: a review. Pain Manag Nurs 2(2):38-46

26. Podsiadlo D, Richardson S (1991) The timed "Up \& Go": a test of basic functional mobility for frail elderly persons. J Am Geriatr Soc 39(2):142-148

27. Prosser L, Canby A (1997) Further validation of the Elderly Mobility Scale for measurement of mobility of hospitalized elderly people. Clin Rehabil 11(4):338-343

28. Tinetti ME (1986) Performance-oriented assessment of mobility problems in elderly patients. J Am Geriatr Soc 34(2):119-126

29. Rommens PM, Hofmann A (2013) Comprehensive classification of fragility fractures of the pelvic ring: recommendations for surgical treatment. Injury. 44(12):1733-1744

30. Wagner D, Kamer L, Sawaguchi T, Richards RG, Noser H, Rommens PM (2016) Sacral bone mass distribution assessed by averaged three-dimensional CT models: implications for pathogenesis and treatment of fragility fractures of the sacrum. J Bone Joint Surg Am 98(7):584-590

31. Wagner D, Hofmann A, Kamer L, Sawaguchi T, Richards RG, Noser H, Gruszka D, Rommens PM (2018) Fragility fractures of the sacrum occur in elderly patients with severe loss of sacral bone mass. Arch Orthop Trauma Surg 138(7):971-977

32. von Friesendorff M, McGuigan FE, Wizert A, Rogmark C, Holmberg AH, Woolf AD, Akesson K (2016) Hip fracture, mortality risk, and cause of death over two decades. Osteoporos Int 27(10):2945-2953

33. Ragnarsson B, Mjöberg B (1992) Arthrosis after surgically treated acetabular fractures. A retrospective study of 60 cases. Acta Orthop Scand 63(5):511-514
34. Janssen MF, Szende A, Cabases J, Ramos-Goni JM, Vilagut G, Konig HH (2018) Population norms for the EQ-5D-3L: a crosscountry analysis of population surveys for 20 countries. The European journal of health economics: HEPAC: health economics in prevention and care

35. Bohannon RW (2006) Reference values for the timed up and go test: a descriptive meta-analysis. J Geriatr Phys Ther 29(2):64-68

36. Helfet DL, Borrelli J Jr, DiPasquale T, Sanders R (1992) Stabilization of acetabular fractures in elderly patients. J Bone Joint Surg Am 74(5):753-765

37. Jeffcoat DM, Carroll EA, Huber FG, Goldman AT, Miller AN, Lorich DG, Helfet DL (2012) Operative treatment of acetabular fractures in an older population through a limited ilioinguinal approach. J Orthop Trauma 26(5):284-289

38. Rickman M, Young J, Bircher M, Pearce R, Hamilton M (2012) The management of complex acetabular fractures in the elderly with fracture fixation and primary total hip replacement. Eur J Trauma Emerg Surg 38(5):511-516

39. Mouhsine E, Garofalo R, Borens O, Fischer JF, Crevoisier X, Pelet S, Blanc CH, Leyvraz PF (2002) Acute total hip arthroplasty for acetabular fractures in the elderly: 11 patients followed for 2 years. Acta Orthop Scand 73(6):615-618

40. Salama W, Mousa S, Khalefa A, Sleem A, Kenawey M, Ravera L, Masse A (2017) Simultaneous open reduction and internal fixation and total hip arthroplasty for the treatment of osteoporotic acetabular fractures. Int Orthop 41(1):181-189

41. Boraiah S, Ragsdale M, Achor T, Zelicof S, Asprinio DE (2009) Open reduction internal fixation and primary total hip arthroplasty of selected acetabular fractures. J Orthop Trauma 23(4):243-248

42. Sermon A, Broos P, Vanderschot P (2008) Total hip replacement for acetabular fractures. Results in 121 patients operated between 1983 and 2003. Injury. 39(8):914-921

43. De Bellis UG, Legnani C, Calori GM (2014) Acute total hip replacement for acetabular fractures: a systematic review of the literature. Injury. 45(2):356-361

Publisher's note Springer Nature remains neutral with regard to jurisdictional claims in published maps and institutional affiliations. 